\title{
Design and experimental validation of a small-scale prototype selective laser sintering system
}

\author{
Abass Enzi ${ }^{1}$. James A. Mynderse ${ }^{2}$ \\ Received: 20 July 2019 / Accepted: 31 October 2019 / Published online: 14 November 2019 \\ (c) Springer Nature Switzerland AG 2019
}

\begin{abstract}
Selective laser sintering (SLS) system is an additive manufacturing technique used in a variety of different applications, such as tool industries, medicine, aerospace, automotive, and electronics. A prototype SLS system was designed, built, and validated to improve SLS-manufactured part quality in terms of porosity and surface roughness. The prototype SLS system was designed for laboratory use only. Critical process parameters were identified to optimize the manufacturing process: forward step, side step, speed, platform temperature, and layer depth. The most essential defects associated with the SLS manufacturing process are porosity, shrinkage, surface roughness, and reduced hardness. The goals of this work were to design and build the prototype SLS system, then to quantify the effects of the selected process parameters on manufacturing defects and minimize manufacturing defects. Validation data from each SLS subsystem was compared to manufacturing simulation program parameters. Validation data included laser power, laser beam diameter, gantry motion in two axes, gantry vibration, and CAD/CAM interface program. Revisions of the prototype SLS system are proposed to maintain the resolution of $0.003 \mathrm{~m}$ and cost of less than $\$ 10,000$.
\end{abstract}

Keywords Additive manufacturing $\cdot$ Selective laser sintering $\cdot$ Rapid prototyping $\cdot$ Experimental validation

\section{Introduction}

Automated systems, such as numerical control (NC), computer numerical control (CNC), and selective laser sintering (SLS), are used in manufacturing plants to produce complex parts with consistently high quality. While CNC mills and lathes are commonly used machines for the production of metallic parts via subtractive manufacturing, SLS is a rapidly growing option for the production of plastic or metallic parts via additive manufacturing. Starting from powdered material, automated SLS machines create 3D parts more complex than is possible with traditional manufacturing processes. Unlike fused-deposition modeling (FDM) 3D printers that have become ubiquitous in classrooms and maker spaces, SLS has the capacity to create functional, metallic parts with good mechanical properties and surface finish. This technique shows exceptional promise to decrease manufacturing process routing and production time for small-volume items.

Many countries are focusing on support research centers that work on developing additive manufacturing techniques for medical parts, civil engineering, fashion design, and manufacturing processes. Additive manufacturing is used widely in laboratories, research centers, and traditional manufacturing plants to produce parts with various materials, low manufacturing cost, and minimum process routing for low-volume or specialty parts. Therefore, additive manufacturing processes are competitive

Electronic supplementary material The online version of this article (https://doi.org/10.1007/s42452-019-1600-3) contains supplementary material, which is available to authorized users.

Abass Enzi, aenzi@ltu.edu | ${ }^{1}$ Department of Production Engineering and Metallurgy, University of Technology, Baghdad, Iraq. ${ }^{2}$ A. Leon Linton Department of Mechanical Engineering, Lawrence Technological University, Southfield, MI 48075, USA. 
with traditional manufacturing methods. SLS remains an expensive process, and there is room for improvement, particularly in the areas of part porosity and surface finish [1].

The most significant advantage of SLS is the ability to efficiently produce a complex part that previously required a long machining time for low-volume production. One example of this type of component is the production tools used in die casting and plastic injection fields. Medical applications include surgical parts and custom prosthetic implants. These benefit from SLS because the parts can be very lightweight with good mechanical properties. SLS applications continue to evolve, and their applications continue to expand with scientific advances in laser technology, engineering software, electronics, and other engineering fields [2].

SLS uses a high-power laser to fuse powdered material into a finished part. SLS could be used to melt different types of materials, such as ceramic, plastic, alloy, and metal. By scanning the laser across a powder bed, the resulting 3D part built layer by layer. The laser tool path is designed using a CAD program with a slicing algorithm and machine-specific tool path [3-7]. One important use of SLS is for applications requiring few parts with high quality and low costs, such as medical, submarine, and aerospace components. SLS does not require specialized tooling to produce parts. Moreover, it is considered a fast technique to provide parts. The advantages of using rapid manufacturing are reduced manufacturing time, manufacturing without tooling and fixtures, producing a part with different materials, and supplying the 3D part (simple or complex) [3].

Many other researchers have worked on SLS and related fields such as multi-axis system design and validation, manufacturing automation control, dynamic analysis, and mechanical design. Afkhamifar et al. worked on the analysis multi-axes automation system. Finite element analysis used to check the automation system and to predict a manufacturing error during running the system [3]. Sarhan et al. [8] studied a gantry system of an automation system. The high surface finish of the gantry system has designed and analyzed. The objective of this paper is to get a minimum frequency during rapid manufacturing. Mao et al. [9] worked on control an automation system. The system was working on five axes. The system features can control all the system axes together to achieve a manufacturing process with high accuracy and easy to operate. Du et al. revised models of synthetic geometry error; the measurement process of multi-axis automation systems by using an encoder has studied in this research. The relationship between the automation motion and error component has calculated while running the system. Also, The validation process applied in 3 axis automation system [10].
The SLS system consists of many parts, such as the structure, laser system, laser positioning system, power distribution system, and electronic control system. Also, the powder bed has a heater system uses to preheat the powder before start fusing powder. Each element of the SLS system has an effect on manufactured part quality. Another significant design concern is system reliability. After designing and building a prototype SLS system, the prototype must be validated before producing $3 \mathrm{D}$ parts and optimizing the manufacturing process.

The overall objective of this research is the optimization of SLS process parameters to improve surface roughness and porosity in finished parts. Five relevant process parameters were identified: side step, forward step, speed, layer depth, and platform temperature [11]. In this work, the design, building, and validation of a desktop-sized prototype SLS system are described. This prototype SLS system has the ability to print parts consisting of more than one material, and the cost of the prototype system is less than commercial systems. Previous work introduced the prototype SLS system but did not include the final design or validation [12]. This prototype SLS system serves as a testbed for additional work on process parameter optimization.

This paper has organized as follows: Sect. 2 describes the SLS defects. Section 3 discusses the prototype SLS system. Section 4 clears computer aided design, computer aided manufacturing validation. Section 5 explained sample artifacts. Section 6 concludes the work.

\section{SLS defects}

Distortion, shrinkage, and warping are the major defects that affect part quality in the SLS process. The shrinkage amount depends on the scanning speed, laser power, and layer thickness. The internal stresses that happen during the printing process lead to distortion and shrinkage [13, 14]. The proposed guidelines about shrinkage, distortion, and warping are [13]: to consider a geometric design, to recognize layer thickness, laser power, scanning speed, and to respect material properties.

The surface roughness value $(\mathrm{Ra})$ is a measure of a part's surface finish. The surface roughness depends on building orientation, layer thickness, and post-processing, etc. The proposed guidelines about the surface finish are: to calculate the desired surface roughness theoretically, to calculate layer thicknesses, and using $90^{\circ}$ of layer angle surface. Each manufacturing process produces different surface properties $[13,15]$.

During the powder melting process, some defects will happen, and one of those defects is porosity. Porosity is generally considered a bad feature because the part quality will decrease with increasing it. There are two types of 
porosity: regular and irregular porosity. For some applications, porosity is considered the desired feature, such as while producing scaffolded parts. For other uses, porosity is regarded as an undesired feature during producing rapid parts [16].

\section{Prototype SLS system}

The prototype SLS system works in four axes: two axes for the laser positioning system, the third axis for layer depth, and the fourth axis for powder distribution, see Fig. 1. The prototype SLS system has a powder feeder mechanism that will move on the XY plane. The piston carries the powder bed and moves on the $z$-axis, and the laser will move on the $X Y$ plane. The printer control is an application that controls the printer processes. From this request, it will feed a slicing tool path to the printer, monitor the printer's axes and manufacturing parameters, and set the printer bed temperature. After these initialization steps, the printer starts to print the 3D part. Within the powder bed, a $10 \mathrm{~W}$ laser fuses the prepared powder into a substantial 3D part. In this work, the powder is made from carbon steel powder mixed with nylon PA650 powder.

The overall system dimensions are selected based on table-top usage in a laboratory to produce parts of small size. The powder bed was sized accordingly. Nylon powder is used as a binder to build parts of different powders, such as steel, ceramic, aluminum, etc. The information in the table was calculated and determined to study surface roughness and crack width of parts that are going to be manufactured by using the SLS prototype system.

Specifications of the prototype SLS system [12]: structural material was steel, communications by USB, file formats was G-Code or wireless electronic handwheel or C language, $152 \times 152 \mathrm{~mm}$ table dimensions, $240 \times 240 \times 70 \mathrm{~mm}$ travel dimensions, required resolution for forwarding step and side step ( $\mathrm{mm} / \mathrm{step}$ ) was $0.003 \mathrm{~mm}$, required resolution ( $\mathrm{mm} / \mathrm{step}$ ) was $0.003 \mathrm{~mm}$, total cost to build SLS prototype system was $\$ 10,000$. The SLS prototype system was designed with a steel frame $305 \times 305 \times 305 \mathrm{~mm}$. Also, the laser positioning system holder has produced by using a 3D printer, see Fig. 2 (see Supplementary Table S1) [12].

\subsection{Laser positioning systems}

There are many types of mechanical systems that convert the microprocessor commands into motion in $X, Y$, and $Z$ directions. Among these types is a ball screw-nut with using a motor to drive the mechanical mechanism. The motor starts rotating after receiving pulses and send rotation to a ball screw. The ball screw is connected to the motor by coupling, and it drives a nut that holds a workpiece table or manufacturing tool. The forward and backward table motion rely on the motor rotation direction, so CW rotation leads to forward motion, and CCW rotation leads to backward motion of the table/holder [17].

The laser positioning system was designed as a twodimensional gantry with size 12 in $\times 12$ in. The system operates in two axes, $\mathrm{X}$-axis, and $\mathrm{Y}$-axis, as shown in Fig. 3 (see supplementary Table S2). Bearings are used on the left and right of the laser holder to get smooth movement. The laser holder the laser and constrains its motion to the XY plane. SolidWorks 2015 used to design all elements of the laser positioning system. The gantry holders and laser holder were manufactured by using 3D printer $[8,18]$.

The accuracy of the automation system is an essential point for the system specifications. The accuracy of the SLS system means forward step and side step in $X$ and $Y$
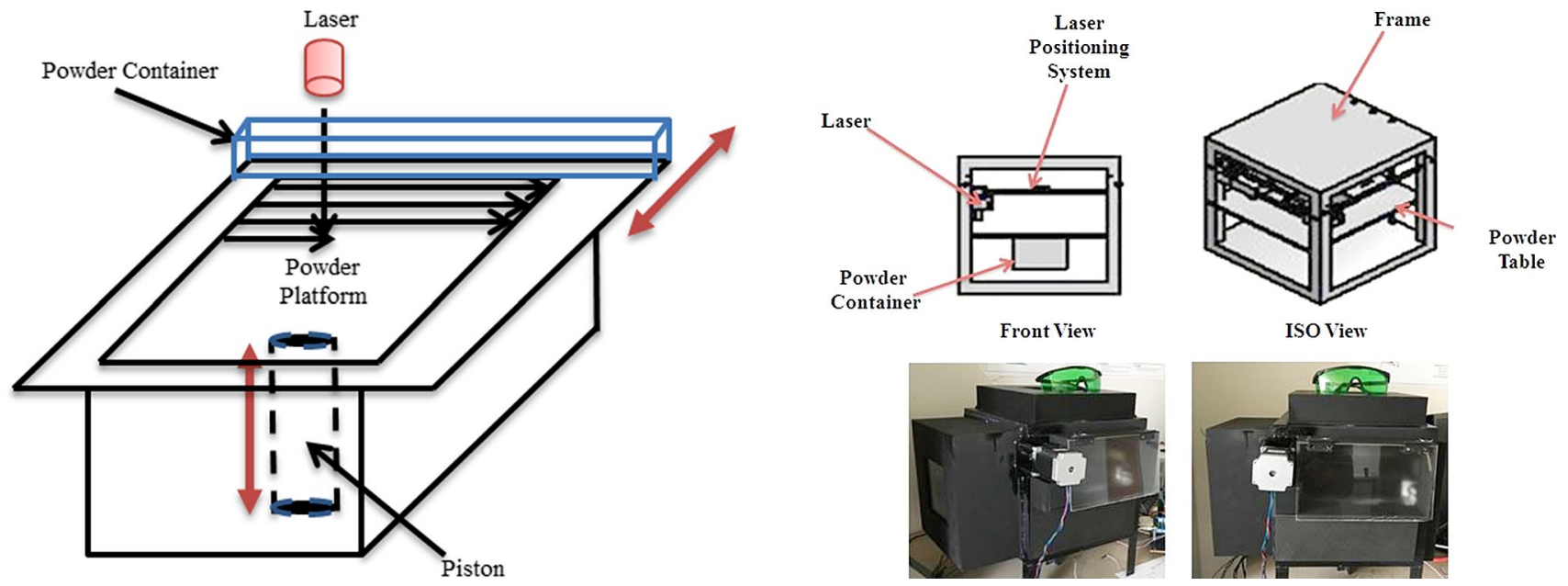

Fig. 1 Schematic representation of an SLS system

Fig. 2 SLS prototype system 


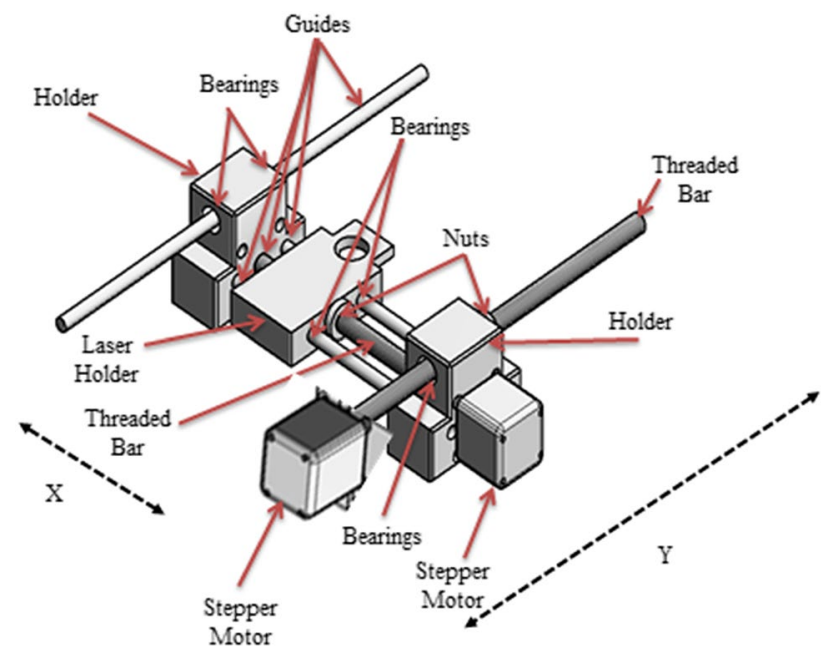

Fig. 3 Gantry system of SLS system

direction, respectively. In this research, the minimum step $(\Delta \mathrm{l})$ in $X$ and $Y$ directions is equal to $0.003 \mathrm{~mm}$ [19]. Equation (1) used to calculate the forward and side step of the threaded bar-nut of the gantry system in $X$ and $Y$ directions [3]. For this work, the motor step angle $\theta_{s}$ was equal to $1.8 \%$ step, and the threaded bar pitch $P B$ was equal to $0.635 \mathrm{~mm}$

$\Delta \mathrm{I}=\frac{\mathrm{PB}}{360} \cdot \frac{\theta_{\mathrm{s}}}{\mathrm{i}}$

where PB is pitch ( $\mathrm{mm} / \mathrm{rev}$ ), $\theta_{\mathrm{s}}$ is step angle o/step, and $\mathrm{i}$ is the gear ratio. One of the validation steps is the measurement of runout on the gantry system by using a dial indicator. The runout of the gantry system in the $\mathrm{X}$-axis was $0.381 \mathrm{~mm}$, and $Y$-axis was $0.762 \mathrm{~mm}$ [12]. Therefore, parts manufactured by using the prototype SLS system will have deviation, and these will affect part length and width. The maximum error due to runout is equal to $0.381 \mathrm{~mm}$ in the $X$ direction and the $0.762 \mathrm{~mm}$ in the $Y$ direction. These errors are very large relative to the designed system of $0.003 \mathrm{~mm}$ due to the low-cost components that used to build the laser positioning system. Future work should focus on improving this error by purchasing high-quality components.

An interface program, stepper motor, motor driver, and Arduino was to be used to validate the minimum step size. The interface program created a pulse chain intended to move the laser positioning system $5 \mathrm{~mm}$. After the laser positioning system stopped the distance that the laser positioning system moved was measured. After running the system, the minimum step measured was $0.003 \mathrm{~mm}$ [12]. This step was consistent with the designed step size. The process was repeated with a $10 \mathrm{~mm}$ movement with no difference in measured step size. Also, the accelerometer type $8692 \mathrm{C} 50$ was used to validate the gantry system vibration in $X, Y$, and $Z$ directions after connecting it to the amplifier KISTLER type 5134. Before measurement, the accelerometer was calibrated with a PCB 394C06 handheld shaker.

Laser holder vibration was measured in $X$ and $Y$ directions with five different motor speeds. Any vibration of the laser holder will manifest as laser positioning error, leading to reduced accuracy and increased surface roughness. Assuming a sinusoidal vibration with measured acceleration specified by amplitude $A\left(\mathrm{~m} / \mathrm{s}^{2}\right)$, frequency $f(\mathrm{~Hz})$, and $t_{s}$ time (s), the acceleration is given by

$\ddot{x}=A \sin \left(2 \pi f t_{s}\right)$

Integrating twice, the displacement is given by

$x=\frac{A}{\left(2 \pi f t_{s}\right)^{2}} \sin \left(\left(2 \pi f t_{s}\right)\right)$

Thus, the maximum tool path error is given by

$x_{\max }=\frac{A}{\left(2 \pi f t_{s}\right)^{2}}$

Maximum tool path error due to vibration in $\mathrm{X}$ direction was $0.736 \mu \mathrm{m}$ when motor speed was $170 \mathrm{~mm} / \mathrm{s}$, and maximum toolpath error in $Y$ direction was $0.012 \mu \mathrm{m}$ when motor speed was $190 \mathrm{~mm} / \mathrm{s}$, see Table 1 (see supplementary Figure S1). These are significantly smaller
Table 1 Frequency and amplitude of the laser positioning system in $X$ and $Y$ direction

\begin{tabular}{lllllll}
\hline & $\begin{array}{l}\text { Linear speed of laser positioning } \\
\text { system }(\mathrm{mm} / \mathrm{s})\end{array}$ & 150 & 160 & 170 & 180 & 190 \\
\hline X-direction & Frequency $(\mathrm{Hz})$ & 230 & 236 & 240 & 255 & 275 \\
& Amplitude $\left(\mathrm{m} / \mathrm{s}^{2}\right)$ & 0.516 & 0.736 & 1.672 & 1.779 & 1.957 \\
& Maximum tool path error $(\mu \mathrm{m})$ & 0.247 & 0.335 & 0.736 & 0.693 & 0.656 \\
Y-direction & 841 & 880 & 955 & 1036 & 1040 \\
& Frequency $(\mathrm{Hz})$ & 0.185 & 0.341 & 0.345 & 0.348 & 0.530 \\
& Amplitude $\left(\mathrm{m} / \mathrm{s}^{2}\right)$ & 0.006 & 0.011 & 0.009 & 0.008 & 0.012 \\
\hline
\end{tabular}


than one step. Therefore, manufacturing defects due to motor induced vibration are assumed to be negligible.

\subsection{Powder distribution system}

Researchers in USA developed and modified powder bed fusion of SLS technology to increase productivity and produce different types of materials. All the powder distribution system has almost the same characteristics that lead to prepare workpiece (powder) and preheating operation to minimize laser power required to start melting the powder. Furthermore, the feeding operation of powder is layer by layer that means distribute powder on the manufacturing table, preheating, then apply laser on powder to fuse the first layer. These processes will be returned until the manufacturing process is completed [17].

In this work, the powder distribution mechanism with size $(280 \mathrm{~mm} \times 280 \mathrm{~mm})$ consists of a powder container with size ( 8 in $\times 1.25$ in $\times 2.5$ in), threaded bar, melting table with size $(114 \mathrm{~mm} \times 127 \mathrm{~mm})$, and stepper motor, see Fig. 4 (see supplementary Table S3). The powder feeder has a container, and the powder will be put in the container manually. After loading powder into the container, the powder feeder moves on the XY plane to distribute powder on the SLS table. The second part of the powder distribution mechanism is the threaded bar that will drive the powder container forward and backward. The container will carry a powder, so when fusing the first layer of powder the platform moves down to feed the second layer by the powder feeder and this process will be repeated until complete a part is formed. For this work, the powder feed was chosen at $200 \mathrm{~mm} / \mathrm{s}$.

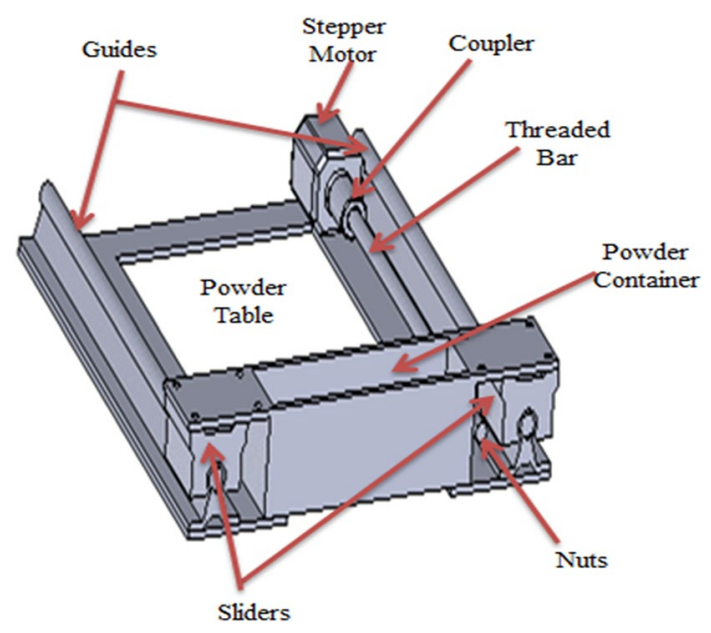

Fig. 4 Powder distribution mechanism
Also, the CAM software is used to control the speed of the power distribution mechanism.

\subsection{Laser analysis}

A high-power laser provides the energy input to melt the powdered material. Therefore, choosing an appropriate high power laser depends on a material melting point and laser beam spot diameter. Furthermore, calculate laser power and laser beam diameter should consider during validate SLS system. The reason for laser validation is to avoid defects that happen during the melting process. The power that needed the laser to fuse the powder calculated by using Eq. (5) [20-22]. Carbon steel mixed with other materials to help a melting process of the powder. Also, the mixed powder needed $10 \mathrm{~W}$ to start fusing powder

$\mathrm{T}_{\mathrm{w}}(\mathrm{t})=\frac{\mathrm{A}_{\mathrm{s}} \mathrm{I}}{\mathrm{K}_{\mathrm{s}}} \delta(\mathrm{t})$

where $A_{s}$ is absorptivity, $I$ is a power density of the laser beam, $\mathrm{K}_{\mathrm{s}}$ is thermal conductivity, and $\delta(\mathrm{t})$ is the temporal function to represent the temperature penetration depth in the solid [22]. The laser specifications used are voltage $D C$ is $12 \mathrm{~V}$, laser wavelength $450 \mathrm{~nm}$, laser power is $10 \mathrm{~W}$, the working temperature is $+10 \sim+40$, driver module is TTL. It can be difficult to find a laser with the desired beam diameter. Instead, one lens was used to reduce the beam diameter to the target value previously calculated.

There are many models used to describe the point heat source [22]. However, they may not apply for some highly conductive materials due to the thermal conduction being non-negligible with respect to fusing depth. Also, the high-speed fusing process is sensitive to the radiation period. These limitations can be avoided by proposed a model of different time-dependent conduction. Equation (6) is used to show the thermal flux area around the heat source during the fusing process. As expected, there is a heat-affected zone on either side of the laser beam location, as shown in Fig. 5. Furthermore, careful selection of laser parameters will minimize the interaction of the thermal flux with previously fused portions of the powder [22]

$T(r, t)-T_{0}=\frac{Q}{4 \pi k t} \exp \left[-\frac{r_{c}^{2}}{4 \propto t}\right]$

where $T_{0}$ is powder bed initial temperature, $Q$ is the intensity of line heat source $(\mathrm{J} / \mathrm{m}), k$ is thermal conductivity $(\mathrm{W} /$ $\mathrm{mK})$, $\mathrm{t}$ is time (s), and $\mathrm{r}$ is cylindrical coordinate $(\mathrm{m})$.

Equation (7) is used to calculate a direct connection between $\mathrm{Q}$ and the Energy Density $\left(\mathrm{J} / \mathrm{mm}^{2}\right)$, as shown 

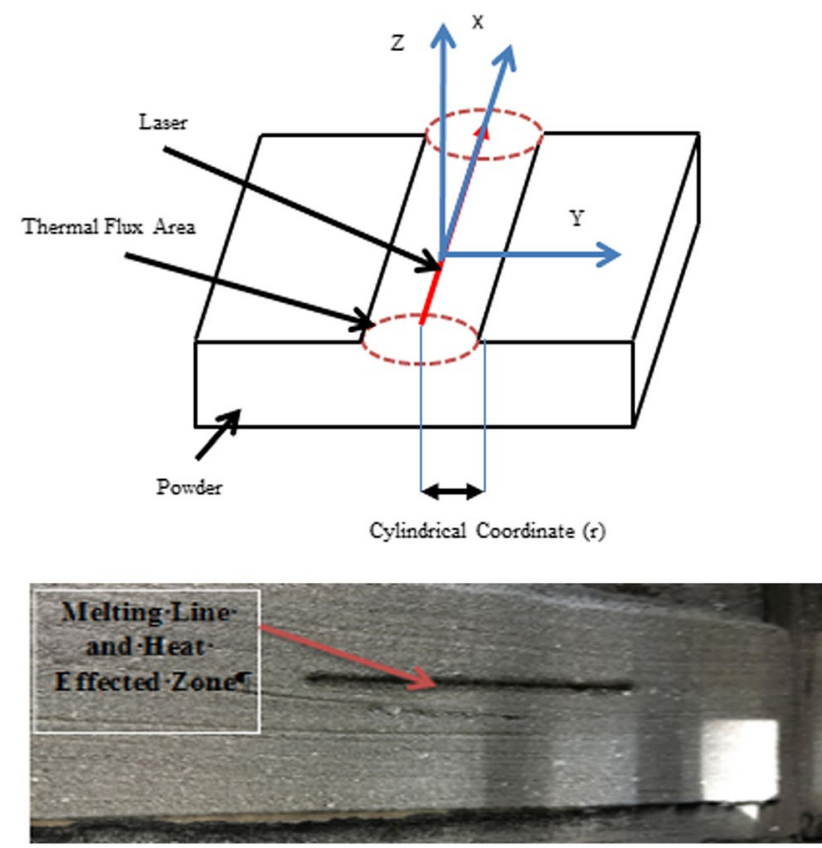

Fig. 5 (Top) thermal flux area and cylindrical coordinate (bottom) experiment to check melting process

below, where $V$ is scanning speed $\mathrm{mm} / \mathrm{s}$, and $\varnothing$ is Spot diameter of laser beam $\mathrm{mm}$.

$E D=\frac{1}{V \times \varnothing}$

The second step was to measure the laser beam spot size. Before starting to use the laser, one must check the laser beam shape. So after checking without a lens, the laser cross-section profile was not circular. It was very close to an ellipse. A circular laser cross-section can be obtained by using a high-quality laser but will be more expensive. For checking laser power, a SPIRICON model SP620U camera was used with filters. A group of four filters (two ND540A, one ND510A, and one ND520A) used to cut power 9-10 times to minimize the laser power because

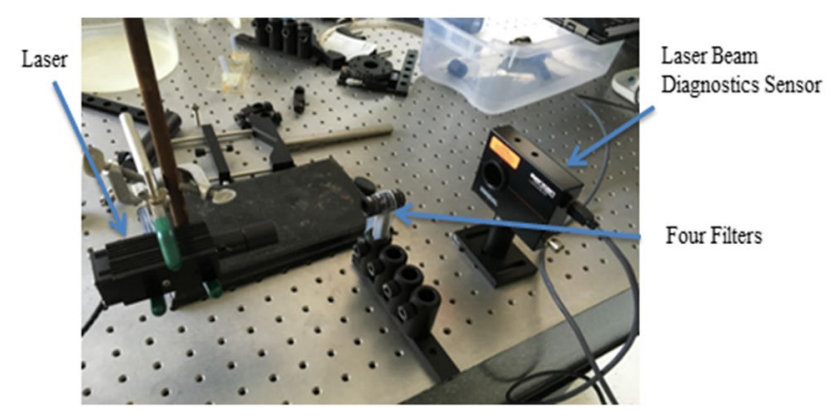

Fig. 6 Validation diagram to measure laser beam diameter the sensor could not measure high power laser. The laser power was measured to be $9.7 \mathrm{~W}$. The configuration of the laser, filters, and diagnostic sensor is shown in Fig. 6.

Also of interest was the laser beam spot profile. Figure 7 shows the laser beam spot by as measured using the Spiricon model SP620U camera. The laser beam shape was not circular, but was instead an ellipse. The laser beam diameter was $0.42 \mathrm{~mm}$ in the major axis and $0.038 \mathrm{~mm}$ in the minor axis by using D4sigma method.

\subsection{Electronic control system}

The electronic control system includes a microprocessor, platform heater, motor drivers, stepper motors, high power laser, power supply, and man machine interface (MMI). The MMI unit is hardware/software used as a link between the SLS system and engineer to observe the machining commands such as speed, feed rate, and editing the part program. The core of the SLS system is microprocessor; it considers a tool to interpret the manufacturing codes that leads to creating enough signals for the axes movement in all directions [17].

Furthermore, The electronic control system provides a link between CAM software and a microprocessor to control $X, Y$, and Z-axis stepper motors, powder distribution motor, and high power laser during the manufacturing process. The electronic platform of the SLS prototype system includes many components working together to build the 3D parts. CAM code language feeds to the microprocessor from a PC to run SLS over USB. Four stepper motor drivers used with the microprocessor to run the system, see Fig. 8.

One of the important things after the design and construction of automated systems is to ensure that the axes work correctly, especially the operating speed to reduce errors during the manufacturing process. Also, the part program data (speed, coordinates, etc.) should be equal to the output data (product dimensions) to avoid product failure.

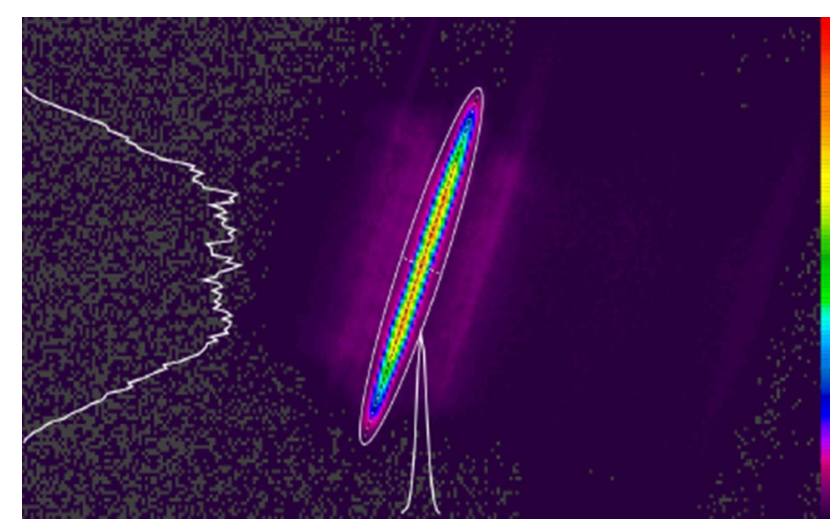

Fig. 7 2D Laser beam 
Fig. 8 The electronic circuit of the SLS system

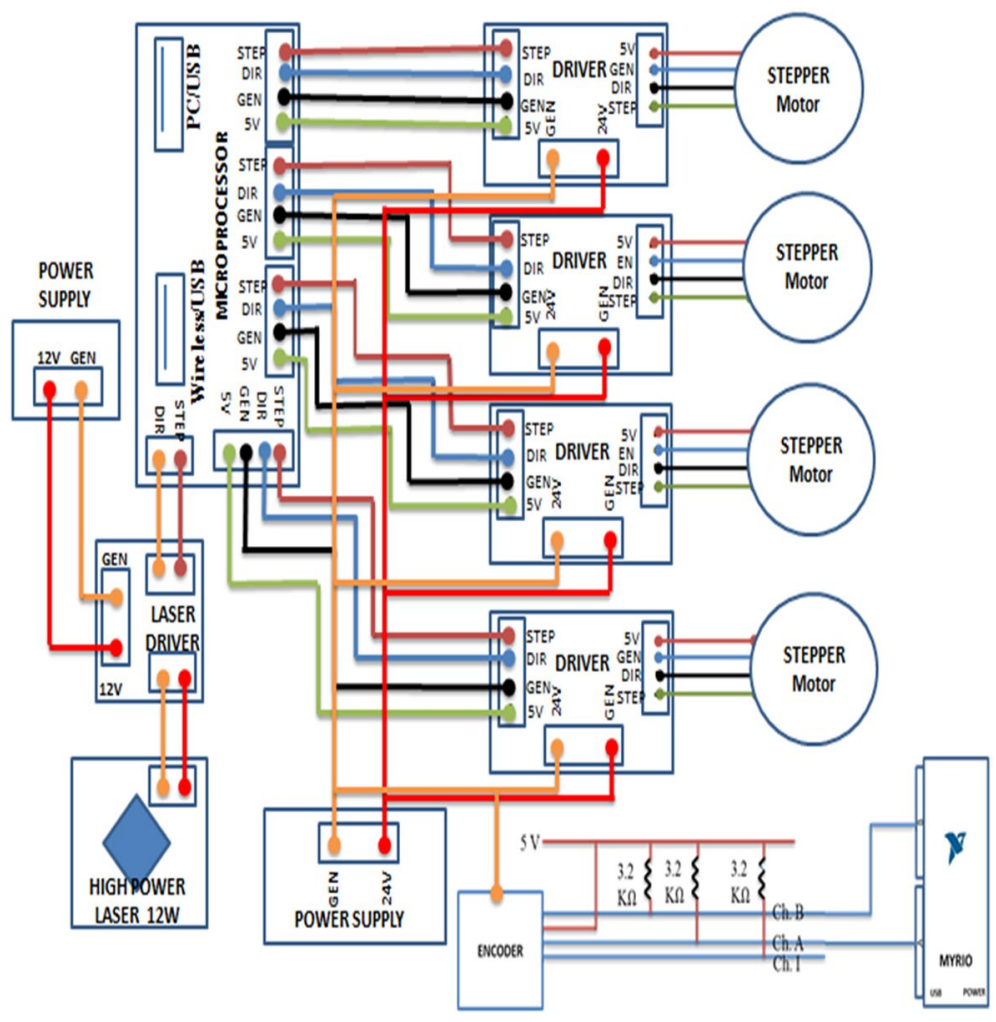

Therefore, the LabVIEW model has built to validate the SLS system before running the SLS system. Figure 9 shows the validation equipment of the stepper motors. The validation process measured stepper motor speed to check how much deviation between input and output speed. Input speed was set by using manufacturing simulation, and output speed was measured from the prototype SLS system. $320 \mathrm{rpm}$ has recorded by using the encoder and LabView code (see supplementary Table S4). Also, Digital Photo Tachometer model \#HPT-100A has used to do a double-check of the result that got from encoder and Labview code, the result that got $320 \mathrm{rpm}$, that means SLS prototype system did not have deviation between input and output speed.

Figure 10 shows the LabView control panel of the FPGA of the stepper motor. Five experiments have used to check gantry speed are $150,160,170,180,190 \mathrm{~mm} / \mathrm{s}$, results recorded from Labview program of the SLS prototype system were $150,160,170,180,190 \mathrm{~mm} / \mathrm{s}$, that means the SLS prototype system is accurate and did not have a deviation between input and output, (see supplementary Figure S3, Figure S4, and Figure S5).

\section{Computer aided design, computer aided manufacturing validation}

As explained previously, the computer aided design is responsible for design $2 \mathrm{D} / 3 \mathrm{D}$ shape, computer process planning that it used for preparing the necessary tools for the manufacturing process, and computer aided manufacturing
Fig. 9 Validation equipment used to validate stepper motor speed

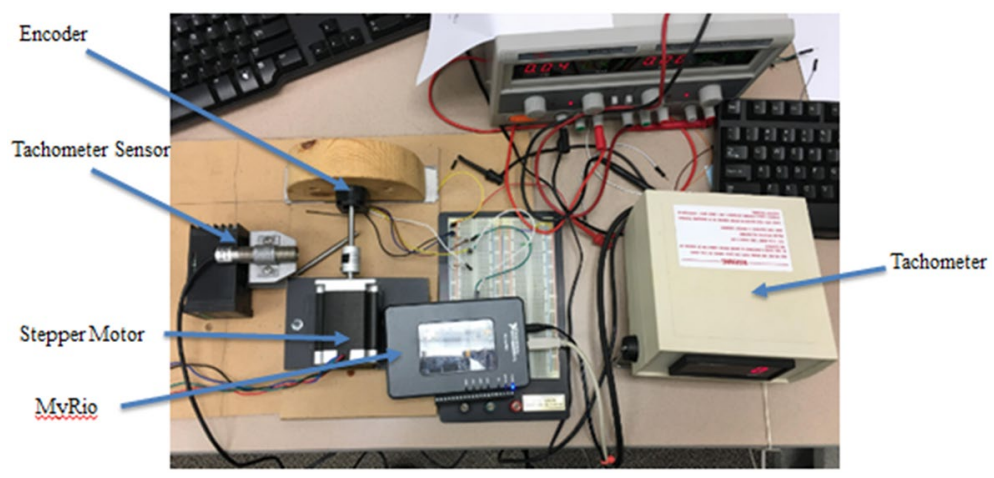

SN Applied Sciences A SPRINGER NATURE journal 


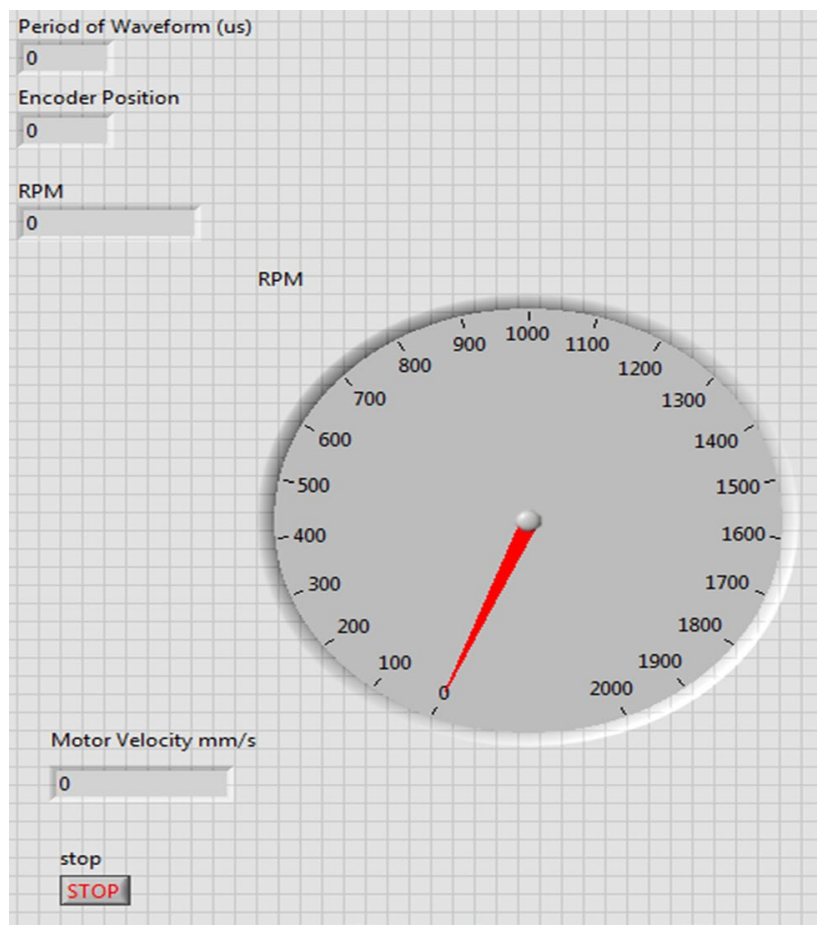

Fig. 10 The LabVIEW control panel of FPGA of the stepper motor

is used to generate the part program to feed it to the SLS system. This process called the offline process. The target of the offline process is to create the part program to manufacture 2D/3D part. The part program contains the dimensions of the designed part, operating speed, feed rate, operating tool number, and other tools necessary for the manufacturing process [17]. Furthermore, the prototype SLS system is connected to a PC, and the setup process of all actuators was between the CAM software and the PC. The running operation of the system was checked before starting to produce the parts, such as axis movement, system speed, platform temperature, and laser ON/OFF of the SLS system. The checking process will happen before running the prototype SLS system. Figure 11 shows the validation flowchart of the manufacturing process of the SLS operation $[7,23]$.

\section{Sample artifacts}

Sample artifacts were created using the prototype SLS system to validate that the overall process was successful. First, the powder was selected. Carbon steel was mixed with PA650 to build a powder that was used as a workpiece to produce the parts. The PA650 material assisted with binding between the steel grains. A scanning electron microscope with energy dispersive X-ray (SEM/EDX) was used to check the chemical composition of the powder before use in the SLS system.

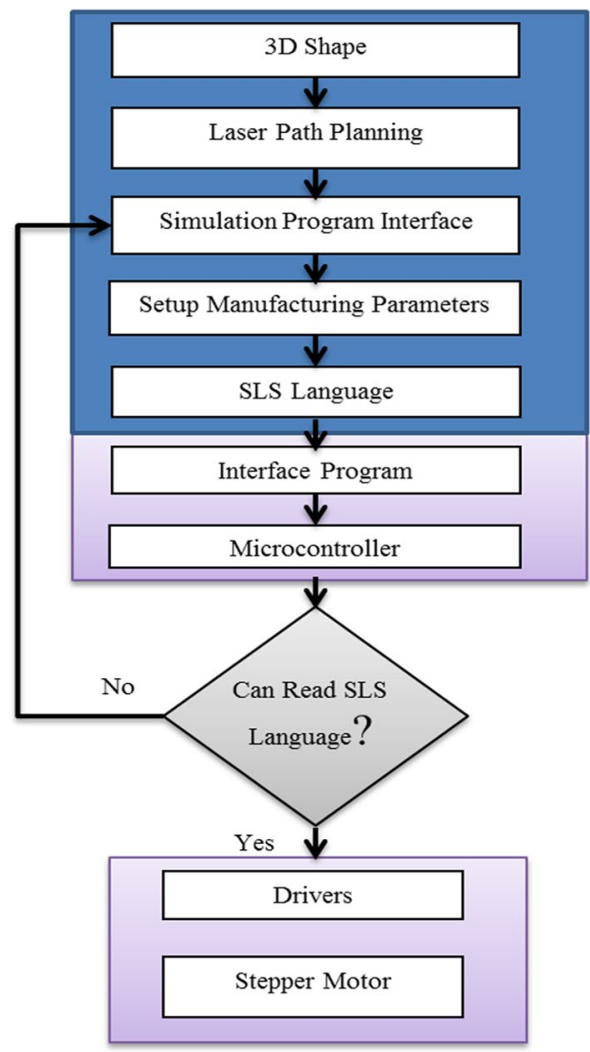

Fig. 11 Flowchart of manufacturing process validation

Figure 12 shows the SEM/EDX chemical analysis of the powder utilized in this research. Table 2 defines the chemical composition of the powder, as determined by the SEM/EDX chemical analysis, in terms of the elements, weight percentage, and component percentage.

The powder was preheated to between 150 and $170^{\circ} \mathrm{C}$; then the SLS process was applied to create rectangular samples. Five samples were in this work with varying manufacturing variables:

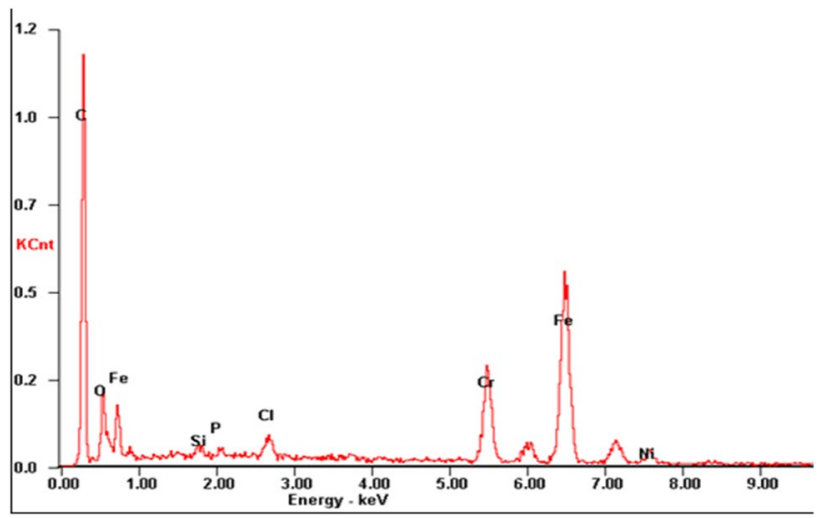

Fig. 12 Powder contents as analyzed by SEM/EDX

\section{SN Applied Sciences}


Table 2 Powder chemical composition

\begin{tabular}{lll}
\hline Element & Weight percentage (\%) & $\begin{array}{l}\text { Atomic } \\
\text { percentage } \\
(\%)\end{array}$ \\
\hline $\mathrm{C}$ & 49.16 & 75.95 \\
$\mathrm{O}$ & 07.82 & 09.07 \\
$\mathrm{~S}$ & 00.60 & 00.40 \\
$\mathrm{P}$ & 00.36 & 00.22 \\
$\mathrm{Cl}$ & 01.11 & 00.58 \\
$\mathrm{Cr}$ & 09.48 & 03.38 \\
$\mathrm{Fe}$ & 28.71 & 09.54 \\
$\mathrm{Ni}$ & 02.75 & 00.87 \\
\hline
\end{tabular}

- Sample 1: side step $1.25(\mathrm{~mm})$, layer depth $1.25(\mathrm{~mm})$, speed $160(\mathrm{~mm} / \mathrm{s})$, platform temp. $155\left({ }^{\circ} \mathrm{C}\right)$, and part length $60(\mathrm{~mm})$.

- Sample 2: side step $1.75(\mathrm{~mm})$, layer depth $1.25(\mathrm{~mm})$, speed $160(\mathrm{~mm} / \mathrm{s})$, platform temp. $155\left({ }^{\circ} \mathrm{C}\right)$, and part length $50(\mathrm{~mm})$.

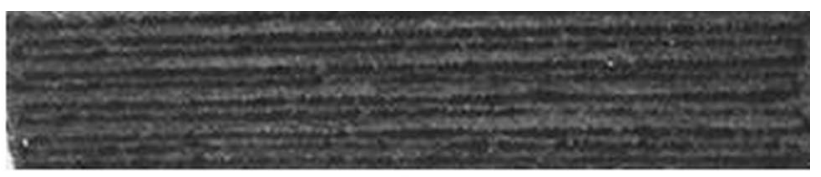

Sample 1

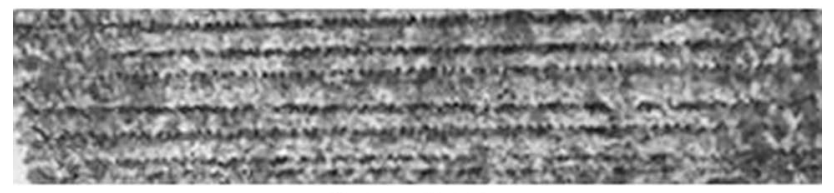

Sample 2

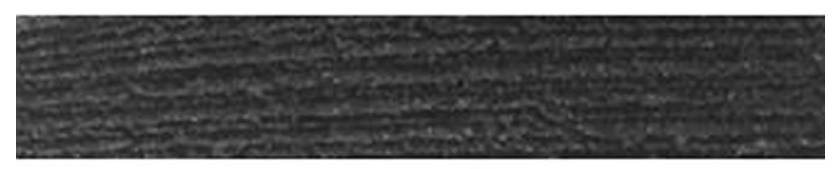

Sample 3

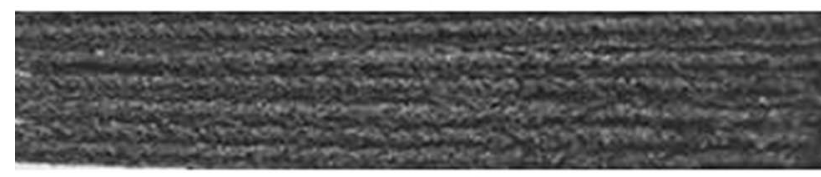

Sample 4

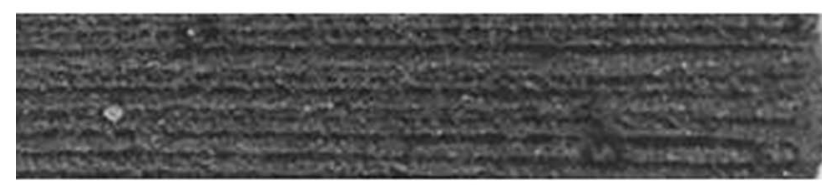

Sample 5

Fig. 13 Specimens with different machining speed
- Sample 3: side step 1 (mm), layer depth $1.5(\mathrm{~mm})$, speed $170(\mathrm{~mm} / \mathrm{s})$, platform temp. $160\left({ }^{\circ} \mathrm{C}\right)$, and part length 55 (mm).

- Sample 4: side step 2 (mm), layer depth $1.5(\mathrm{~mm})$, speed $170(\mathrm{~mm} / \mathrm{s})$, platform temp. $160\left({ }^{\circ} \mathrm{C}\right)$, and part length 55 (mm).

- Sample 5: side step $1.5(\mathrm{~mm})$, layer depth 1 (mm), speed $170(\mathrm{~mm} / \mathrm{s})$, platform temp. $160\left({ }^{\circ} \mathrm{C}\right)$, and part length 55 $(\mathrm{mm})$.

Figure 13 shows photos of the resulting artifacts. Traces from the laser pattern are shown and samples varied in surface roughness.

\section{Conclusions}

This paper presented the design and validation of a prototype SLS system for the purpose of optimizing process parameters to minimize porosity and surface roughness defects. After building the prototype SLS system, it was tested against design specifications.

The minimum forward and sidestep was $0.003 \mathrm{~mm}$. The laser spot dimensions were $0.420 \mathrm{~mm}$ and $0.038 \mathrm{~mm}$ in the primary and microns axis respectively, and laser power was $9.7 \mathrm{~W}$. Scanning electron microscopy was used for analyzing printed samples tested to determine part quality after melting process. The primary limitation of the prototype SLS system was the error due to runout associated with the low-cost components selected. Future work will focus on improving these errors without significantly increasing the prototype cost.

Funding This study was supported by the Higher Committee of Education Development in Iraq (HCED) and Metaldyne Performance Group, Inc. (MPG).

\section{Compliance with ethical standards}

Conflict of interest The authors declare that they have no conflict of interest.

\section{References}

1. Li J, Myant C, Wu B (2016) The current landscape for additive manufacturing research. Imperial College Additive Manufacturing Network, UK

2. Gu D (2015) Laser additive manufacturing of high-performance materials. Springer, Berlin

3. Afkhamifa A, Antonelli D, Chiabert P (2016) Variational analysis for CNC milling process. In: 14th CIRP conference on computer aided tolerancing, Procedia CIRP

4. Medellín-Castillo HI, Torres JEP (2009) Rapid prototyping and manufacturing: a review of current technologies. In: 
Proceedings of the ASME international mechanical engineering congress \& exposition

5. Rochus P, Plesseria J-Y, Van Elsen M, Kruth J-P, Carrus R, Dorma T (2007) New applications of rapid prototyping and rapid manufacturing (RP/RM) technologies for space instrumentation. Acta Astronaut 61:352-359

6. Davim JP (2013) Lasers in manufacturing. Wiley, New York

7. Gibson I, Rosen DW, Stucker B (2010) Additive manufacturing technologies. Springer, New York

8. Sarhan AAD, Besharaty SR, Akbaria J, Hamdi M (2015) Improvement on a CNC gantry machine structure design for higher machining speed capability. Int J Mech Aerosp Ind Mechatron Manuf Eng 9:577-581

9. Mao J, Chenb X, Feng W, Yuan S, Du R (2015) A precision CNC turn-mill machining center with gear hobbing capability. Precis Eng 41:126-134

10. Du Z, Zhang S, Hong M (2010) Development of a multi-step measuring method for motion accuracy of NC. Int J Mach Tools Manuf 50(3):270-280

11. Enzi A, Mynderse JA (2017) Optimization of process parameters applied to a prototype selective laser sintering system. In: ASME 2017 international mechanical engineering congress and exposition, Tampa, Florida, USA, 2017

12. Enzi A, Mynderse JA (2016) Design of a prototype selective laser sintering system for process parameter optimization. In: Proceedings of the international conference on industrial engineering and operations management, USA

13. Zaragoza-Siqueiros J, Medellín-Castillo HI (2014) Design for rapid prototyping, manufacturing and tooling: guidelines. In: Proceedings of the ASME 2014 international mechanical engineering congress and exposition
14. Lu L, Fub J, Nee A, Kang E, Miyazawa T, Cheah C (1995) Origin of shrinkage, distortion, and fracture of photopolymerized material. Mater Res Bull 30(12):1561-1569

15. Ahn D, Kim H, Lee $S$ (2007) Fabrication direction optimization to minimize post-machining in layered manufacturing. Int J Mach Tools Manuf 47(3-4):593-606

16. İlkgün Ö (2005) Effects of production parameters on porosity and hole properties in laser sintering rapid prototyping process. M.Sc. Thesis, Middle East Technical University

17. Suh SH, Kang SK, Chung DH, Stroud I (2008) Theory and design of CNC systems. Springer, Berlin

18. Hui GM (2013) Dynamics analysis of 3 axis gantry type multipurpose CNC machine, University Malaysia Pahang

19. Altintas $Y$ (2012) Manufacturing automation. Cambridge University Press, Cambridge

20. Steinmeier DW, Schaller $L$ (2015) Validating the laser welding process: a case study. In: micro Joining Solutions and HealthTronics

21. Gusarov AV, Yadroitsev I, Ph B, Smurov I (2009) Model of radiation and heat transfer in laser-powder interaction zone at selective laser melting. In: ASME, vol 131

22. Franco A, Lanzetta $M$, Romoli $L$ (2010) Experimental analysis of selective laser sintering of polyamide powders: an energy perspective. J Clean Prod 18:1722-1730

23. Simchi A (2006) Direct laser sintering of metal powders: mechanism, kinetics and microstructural features. Mater Sci Eng 428(1-2):148-158

Publisher's Note Springer Nature remains neutral with regard to jurisdictional claims in published maps and institutional affiliations. 